\title{
Autour des objets au Moyen Âge : entre nature et culture
}

Projet collectif de recherches de l'équipe des médiévistes d'ARTeHIS

UMR 5594

\section{Eliana Magnani et Daniel Russo}

\section{(2) OpenEdition}

Journals

Édition électronique

URL : https://journals.openedition.org/cem/7222

DOI : $10.4000 /$ cem.7222

ISSN : 1954-3093

Éditeur

Centre d'études médiévales Saint-Germain d'Auxerre

Édition imprimée

Date de publication : 15 août 2008

ISSN : 1623-5770

Référence électronique

Eliana Magnani et Daniel Russo, « Autour des objets au Moyen Âge : entre nature et culture », Bulletin du centre d'études médiévales d'Auxerre | BUCEMA [En ligne], 12 | 2008, mis en ligne le 02 juillet 2008, consulté le 22 septembre 2022. URL : http://journals.openedition.org/cem/7222 ; DOI : https://doi.org/ 10.4000/cem.7222

Ce document a été généré automatiquement le 22 septembre 2022.

\section{(c) (i) ()}

Creative Commons - Attribution - Pas d'Utilisation Commerciale - Partage dans les Mêmes Conditions 4.0 International - CC BY-NC-SA 4.0

https://creativecommons.org/licenses/by-nc-sa/4.0/ 


\title{
Autour des objets au Moyen Âge : entre nature et culture
}

\author{
Projet collectif de recherches de l'équipe des médiévistes d'ARTeHIS \\ UMR 5594
}

\author{
Eliana Magnani et Daniel Russo
}

1 Dans le cadre de la définition d'un sujet commun de réflexion, faisant valoir ses différentes compétences dans les domaines de l'archéologie, de l'histoire, de l'histoire de l'art, de la musicologie et de la conservation du patrimoine, l'équipe des médiévistes d'ARTeHIS UMR $5594^{1}$, a pris « l'objet » comme élément pouvant articuler autour d'une même enquête, entre elles, différentes disciplines et ainsi contribuer à définir un projet commun, depuis le Néolithique jusqu'au Moyen Âge, sur les rapports entre «nature et culture ».

2 Fondée d'abord sur une approche historiographique de la notion d'objet, qui distingue ses modes d'émergence dans les discours profane et scientifique, technique, dès la fin du XVIII siècle, cette enquête porte sur le statut élaboré des objets dans l'écologie des sociétés médiévales, dans leurs rapports à l'environnement et dans leurs modes de compréhension de l'humain. L'accent est mis sur l'inventaire des sources écrites (archives, textes narratifs...) et le vocabulaire utilisé, sur la documentation visuelle qu'il est possible de réunir et d'analyser - enluminures de manuscrits, peintures murales et sur bois, et autres supports artistiques -, de même que sur les témoins conservés de la production matérielle, en vue d'établir une grille de lecture fondée sur l'interaction raisonnée des textes, des images, et des matières transformées. Trois grandes lignes d'études sont ainsi privilégiées : la première, à partir des textes et des images, vise à l'entendement des realia, ou des "existants", selon le terme employé par Philippe Descola (2005), dans la longue durée de la période médiévale ; la deuxième sert à mieux distinguer, à travers l'approche interdisciplinaire, le statut de l'objet en suivant ses différentes déclinaisons dans le champ des pratiques sociales et dans celui des manifestations sensibles de ces realia; la dernière est davantage axée sur les savoirfaire techniques et matériels qui entourent l'objet au Moyen Âge. 
3 Depuis 2007, au rythme de trois réunions par an, différents dossiers ont déjà été discutés. Il a été question, entre autres, des plaque-boucles mérovingiennes (P. Chopelain), des sarcophages en pierre du haut Moyen Âge (S. Büttner et F. Henrion), de l'objet dans les manuscrits d'époque carolingienne (D. Russo), de la réification des reliques (M.-C. Isaia), des objets dans les inhumations (P. Chevalier et F. Ravoire), d'épigraphie et de «listes" des objets et des biens dans le haut Moyen Âge (E. Magnani), des sceaux de l'âge seigneurial (M. Billoré), des objets sonores médiévaux (M. Clouzot), des manuscrits enluminés à la fin du Moyen Âge (B. Beys, D. DonadieuRigaut) et des costumes dans la documentation comptable du duché de Bourgogne au $\mathrm{XV}^{\mathrm{e}}$ siècle (S. Jolivet).

\section{NOTES}

1. Pour plus d'informations sur la composition et les axes de recherche de l'équipe, voir : « http://www.artehis.cnrs.fr/recherche/equipe4/equipe4Pres2.html ».

INDEX

Mots-clés : objet 